\title{
"En sociedades polarizadas, los polos que crecen son los que soportan las diferencias que establece la nueva circulación del sentido". Entrevista a Mario Carlón
}

\author{
"In polarized societies, the poles that grow are those that support the differences \\ established by the new circulation of meaning". Interview with Mario Carlón
}

https://doi.org/10.22235/d34.2588

\author{
Gastón Amen \\ ORCID: 0000-0001-5411-3965
}

Universidad de la República, Uruguay.

\begin{abstract}
RESUMEN
En esta entrevista al investigador argentino Mario Carlón se dialoga sobre diversos asuntos vinculados a la circulación del sentido en las sociedades contemporáneas, línea de investigación en la que viene trabajando desde hace varios años. Algunos temas que se tratan son los principales aportes de su reciente libro, Circulación del sentido y construcción de colectivos en una sociedad hipermediatizada (Nueva Editorial Universitaria, 2020); los desafíos analíticos derivados de la presencia de diversos sistemas mediáticos (medios masivos, redes sociales mediáticas, sistema underground) en las sociedades actuales, hipermediatizadas, en las que existen asimismo múltiples enunciadores, tanto individuales como colectivos, con una gran e inédita producción de contenidos; la influencia de Eliseo Verón en su obra; su reflexión acerca de la influencia del pensamiento peirceano en América Latina; el fenómeno de la polarización en sociedades que se caracterizan por la circulación del sentido como diferencia, entre otros temas. A través de esta entrevista se busca contribuir al diálogo informado y el intercambio constructivo en el campo de los estudios de la comunicación.
\end{abstract}

Palabras clave: circulación del sentido; mediatización; sociedades hipermediatizadas; contemporaneidad; polarización.

\begin{abstract}
This interview with Argentine researcher Mario Carlón discusses various issues related to the circulation of meaning in contemporary societies, a line of research he has been working on for several years. Some of the topics discussed are the main contributions of his recent book, Circulacion del sentido y construcción de colectivos en una sociedad hipermediatizada (Nueva Editorial Universitaria, 2020); the analytical challenges derived from the presence of diverse media systems (mass media, social media networks, underground system) in today's hypermediatized societies, in which there are also multiple enunciators, both individual and collective, with a large and unprecedented production of contents; the influence of Eliseo Verón in his work; his reflection on the influence of Peircean thought in Latin America; the phenomenon of polarization in societies characterized by the circulation of meaning as difference; among other topics. This interview seeks to contribute to informed dialogue and constructive exchange in the field of communication studies.
\end{abstract}

Keywords: circulation ofmeaning;mediatization; hypermediatized societies; contemporaneity; polarization.

Cómo citar: Amen, G. (2021). "En sociedades polarizadas los polos que crecen son los que soportan las diferencias que establece la nueva circulación del sentido". Entrevista a Mario Carlón. Dixit, 34, 95-104. https://doi.org/10.22235/d34.2588

Recepción: 12/04/2021 :: Aceptación: 01/06/2021 
El contexto de esta entrevista está signado por la publicación reciente de su último libro, Circulación del sentido $y$ construcción de colectivos en una sociedad hipermediatizada (Nueva Editorial Universitaria, 2020), así como por su próxima participación como conferencista inaugural en el XVIII Encuentro Latinoamericano de Facultades de Comunicación Social (FELAFACS). Este evento se realizará en Montevideo del 6 al 8 de octubre de 2021, organizado por la Facultad de Información y Comunicación de la Universidad de la República, con el apoyo y la participación de la Facultad de Derecho y Ciencias Humanas de la Universidad Católica del Uruguay, de la Facultad de Comunicación y Diseño de la Universidad ORT Uruguay y de la Facultad de Comunicación de la Universidad de Montevideo.

Esta entrevista con Mario Carlón aporta, entre otros asuntos, elementos para el diálogo y debate regional respecto de su novedoso dispositivo analítico, presentado en su último trabajo, para abordar los fenómenos vinculados a la circulación del sentido en las sociedades contemporáneas, caracterizadas por la presencia de diversos sistemas mediáticos (medios masivos, redes sociales mediáticas, sistema underground). A través del diálogo informado y del intercambio constructivo, el campo de los estudios de la comunicación puede desarrollarse virtuosamente.

-Has investigado y publicado en torno a lo televisivo, sobre el fin de los medios masivos, acerca del desarrollo de una perspectiva no antropocéntrica sobre la post-tv, el post-cine, YouTube. Ahora te has volcado al estudio de los procesos de circulación del sentido ¿qué te llevó a enfocar hacia allí tus actuales investigaciones y qué continuidades o rupturas encontrás con respecto a tus anteriores trabajos?

-En cuanto a trabajos anteriores es un cambio de foco, como bien planteás. Las investigaciones sobre circulación del sentido no son sobre medios, aunque para ser realizadas deben partir de un diagnóstico sobre el funcionamiento de la mediatización, que debe estar actualizándose constantemente porque ha cambiado mucho y sigue cambiando. La clave está en que los estudios sobre circulación del sentido difieren de los históricos análisis sobre la producción del sentido, que tanta influencia han tenido en el amplio campo de las ciencias sociales. Fueron propuestos, como yo intento llevarlos a la práctica, por Eliseo Verón, cuando distinguió en la década del ochenta "producción", "reconocimiento" y “circulación”. Y están creciendo y expandiéndose significativamente, porque permiten pensar desde nuevos ángulos los vínculos entre los estudios sobre el sentido y los "actores sociales”. Así permiten focalizar, de modo actualizado, las principales transformaciones contemporáneas, desde la emergencia de actores/enunciadores individuales (como youtubers, instagrammers, tuiteros, etcétera) y colectivos (movimientos de género, comunidades de fans, etcétera) incluyendo a los desarrollos de los nuevos movimientos identitarios, sociales y políticos que, más allá de la posmodernidad, se despliegan gracias a las transformaciones que han habilitado fenómenos como el uso generalizado de smartphones e Internet. Como en este campo hay prácticamente una revolución conceptual debido a que hay nuevas formas de conceptualizar articulaciones entre el sentido y las transformaciones sociales, podemos detenernos en ellas.

\section{-De acuerdo.}

-Los análisis en producción se ocupan principalmente de las relaciones que los discursos mantienen con otros anteriores, que han sido sus condiciones de producción. Según esta teoría, la tarea del analista consiste en determinar las marcas que se encuentran en el discurso para luego convertirlas en "huellas", operación que realiza al establecer qué discursos fueron sus condiciones de producción. Podemos pensar en este nivel en nociones como "intertextualidad" e "interdiscursividad". Ubicamos en este campo a los tradicionales análisis sobre el sentido o la significación que se ocuparon, en la era de los medios masivos, de abordar la literatura, el cine, el periodismo, la televisión, la radio, el documental, etcétera, análisis de los discursos o de la producción del sentido con capacidad de generar corpus precisos para estudiar y que siguen siendo muy importantes. 
Los estudios en reconocimiento se ocupan de otros discursos, los que se producen a partir del discurso-objeto inicial. Para poder realizarlos debe constituirse un nuevo corpus, compuesto por los discursos que se generaron a partir de la existencia del primero. Por ejemplo, en el campo del cine, pueden ocuparse de las críticas profesionales que se publican cuando se estrena una película y, actualmente, de los comentarios que los amateurs dan a conocer en las redes sociales. En un sentido más amplio, podemos vincular estos análisis con los estudios en recepción propios del reception turn de los años ochenta y noventa. Por una razón de costos, en la era de los medios masivos fueron menos frecuentes en el campo académico, sobre todo aquí en América Latina, aunque han tenido un gran desarrollo en el campo de la investigación privada con fines comerciales (a través de entrevistas, focus groups, etcétera).

Lo propio de la perspectiva de Verón es que insistió mucho en la no linealidad de la circulación del sentido. La circulación, para Verón, es el nombre de una diferencia: la que se produce entre producción y reconocimiento. Esto quiere decir que, para él, no se puede predecir, a partir del análisis de un discurso, qué va a suceder con su circulación, qué efectos va a tener. Para avanzar en esta dirección hay que generar un nuevo corpus y estudiar otros discursos. De la circulación no hay huellas, es invisible. Se estudia a partir de un análisis de las diferencias que se producen entre un discurso y el que le sigue o los que le siguen. También es característico de su enfoque que, para él, esta diferencia no es un fenómeno excepcional sino estructural, frecuente en situaciones mediatizadas y no mediatizadas porque producción y reconocimiento son lugares diferentes en la red semiótica, que son ocupados por actores/enunciadores distintos, con emplazamientos espacio-temporales específicos y en circunstancias diferentes.

Dos cuestiones motivaron que pasara a ocuparme en estos años de los nuevos estudios sobre circulación. Una de ellas fue que estos estudios fueron impulsados nuevamente por Verón, quien propuso que fueran tema de un simposio organizado por CISECO que se desarrolló en $2016^{1}$ y en el que participé. En este proceso fueron muy importantes también otros investigadores, como el presidente de CISECO, Antônio Fausto Neto, e intelectuales como José Luiz Braga. La otra es el cambio que se produjo en la última década, sobre todo a partir de la emergencia de las redes sociales mediáticas (Facebook, YouTube, Instagram, Twitter...) que, desde mi punto de vista, hizo evidente la necesidad de actualizar e impulsar los estudios sobre circulación. Desde la emergencia de las redes sociales mediáticas se comenta permanentemente lo que se publica en los medios masivos. Y al revés, en los medios masivos se retoma lo que se dice en las redes. Entonces, lo que sucedió fue que un fenómeno que era "invisible" y que no era tan fácil de estudiar quedó a la luz, expuesto. Basta con ver un hilo de Twitter o en Facebook para advertir que es un fenómeno menos complejo. Hay un discurso, al cual le sigue otro, y luego otro. Podemos constatar la diferencia en la pantalla de un celular. Lo que he intentado hacer en estos años al concentrarme en los estudios sobre la circulación fue ocuparme de un fenómeno que considero constitutivo de la cultura contemporánea: el sentido circula. Pero no lo hace como expansión de ninguna narrativa, si por eso se entiende como efecto de algo que se controla o planifica desde la producción. Lo que domina es siempre la diferencia.

-Cuando resaltás la importancia del fenómeno de la diferencia en la circulación del sentido, recuerdo un interesante trabajo de Guy Debrock (1991), La Información y el estatuto metafísico de los signos, en el que cuestiona tanto lo que denomina una "metafísica de la sustancia" como la que llama una "metafísica de los hechos", las cuales no consiguen dar cuenta de la realidad en su constante proceso de transformación. En cambio, reivindica lo que nombra como una "metafísica

$1:$ : CISECO es el Centro Internacional en Semiótica y Comunicación, con sede en Japaratinga (Brasil), que Verón y Antonio Fausto Neto fundaron en 2009 y que, durante diez años, organizó simposios anuales denominados "Pentálogos". Los simposios "A circulação discursiva: entre produção e reconhecimento" (2016) y "Circulação discursiva e transformação da sociedade" (2017) fueron dedicados a la circulación. 
de los eventos", que se sustentaría básicamente en la semiótica de Charles Peirce, que sí conseguiría dar cuenta de la realidad cambiante, de acuerdo con Debrock, al basarse en una lógica procesual, en la que la concepción triádica del signo es medular. En este sentido, te quería preguntar si no podría establecerse una vinculación entre la concepción de la diferencia que planteás, en un sentido veroniano, con la idea defendida por Debrock, basada en la semiótica de Peirce, la cual resalta la importancia de los eventos, de lo que sucede, para abordar el devenir en el que consiste la realidad, eventos en los que la idea de diferencia tiene una importancia central. En su discurrir, los eventos generan nuevos eventos, los que producen diferencias a través de la generación de nuevas representaciones e interpretantes, los cuales continúan a su vez este proceso. No hablo aquí, obviamente, más que del concepto de semiosis de Peirce. ¿Puede vincularse esta concepción peirceana de la semiosis o "metafísica de los eventos", como la llama Debrock, con la perspectiva que desarrollás para abordar la circulación del sentido en la contemporaneidad? La vinculación con Peirce, por otra parte, recuerdo que fue planteada por Fernando Andacht en la presentación de tu último libro, hace unos meses en la UBA Sociales, en el marco del ciclo "Diálogos virtuales en la Biblioteca". ¿Cómo ves esta potencial vinculación conceptual? ¿Es posible?

-Es singular lo que sucede con el pensamiento peirceano. Concentrémonos en lo que sucede en América Latina, donde es innegable su influencia epistemológica. No podemos soslayar que importantes intelectuales latinoamericanos de gran influencia en los estudios sobre los lenguajes, las ciencias sociales y la comunicación como Andacht, Verón o Lucía Santaella se hayan apoyado en él y hayan demostrado su vigencia a lo largo de las décadas. Yo no me considero un experto en Peirce, pero es evidente la influencia que autores peirceanos han ejercido en mi obra, interesada por discursos que contienen imágenes. Rápidamente puedo citar aquí, para sumar a otro autor, esta vez no latinoamericano, a Jean-Marie Schaeffer y su extraordinario libro de la fotografía, ${ }^{3}$ en el que la considera un signo de recepción.

Ahora, retomando tu pregunta, es claro que lo que señaló Andacht ese día con tanta precisión y maestría exponiendo ejemplos tan pertinentes e interesantes fue acertado, porque puso acento en el fundamento de los estudios sobre circulación. Recordemos que Verón -en cuya obra me apoyé para desarrollar un dispositivo analítico en mi último libro- cuando expuso su clásico modelo de "unidad mínima” de la red discursiva en 1987, presentó un esquema que contiene dos veces el gráfico triádico de Peirce. Entonces esto que señalás, de que la concepción triádica del signo es medular, es absolutamente cierto. Tanto como que este tipo de análisis resalta la importancia de los eventos, de lo que sucede, de lo procesual para abordar el devenir de la realidad; realidad que para Verón se construía para una sociedad en tanto "experiencia colectiva” en gran parte por la acción de los medios, como sostuvo en Construir el acontecimiento. En términos epistemológicos podría decirse también -estoy pensando en algunos textos que se han publicado en estos años sobre Teorías de Redes- que es una perspectiva teórica relacionista y no sustancialista, es decir, que sostiene el carácter cambiante y dinámico de todas las unidades de

2:: Evento virtual de presentación del libro Circulación del sentido y construcción de colectivos en una sociedad hipermediatizada, de Mario Carlón, realizado el 28 de octubre de 2020 en el marco del ciclo "Diálogos virtuales en la Biblioteca" y organizado por la Facultad de Ciencias Sociales UBA (2020).

3:: A partir de las clasificaciones del signo de Peirce, Schaeffer (1990) caracteriza a la imagen fotográfica como un signo icónico indicial, a la vez que la entiende como un signo de recepción, pues considera que es imposible comprenderla desde una perspectiva que defina el signo en función de su emisión. Afirma que un signo no tiene más existencia que para un interpretante, al menos virtual, así como destaca la flexibilidad pragmática de la fotografía como lugar de significación y, por tanto, el estatuto cambiante y múltiple de la imagen fotográfica, gestión en la que desarrolla nociones muy importantes como saber lateral y dinámicas receptivas. 
observación, que mutan permanentemente. Y ese es, en mi opinión, uno de los fundamentos de su vigencia. Apoyándose en estos principios, los estudios sobre circulación del sentido actuales pueden dar cuenta ya no solo de lo que se ocupaban los tradicionales, que se restringían a la producción del sentido, sino de la dimensión diacrónica en la que se despliegan y se construyen los intercambios mediatizados y discursivos efectivos entre los medios, los colectivos, las instituciones y los individuos (además de las intervenciones automáticas en las redes sociales). Este es uno de los sentidos en que puede decirse que este enfoque es epistemológicamente novedoso.

En un estudio que presentamos en Brasil el año pasado sobre la construcción contemporánea de los acontecimientos (Midiaticom, 2020), en el que analizamos lo sucedido con el discurso de apertura de las sesiones ordinarias en el Congreso de la Nación en 2020, enunciado por el presidente Alberto Fernández, pudimos corroborar, una vez más, el poder de este tipo de análisis. El estudio de la circulación nos permitió dar cuenta de la complejidad de los flujos de sentido que se desencadenan en un acontecimiento mediatizado. Así, identificamos los flujos "hacia arriba" y "hacia abajo" que circularon entre diferentes sistemas mediáticos (de los medios masivos a las redes sociales mediáticas y viceversa). Analizamos cómo flujos de sentido que partieron de las redes sociales de la Casa Rosada llegaron a los canales de televisión (gracias al hashtag \#AsambleaLegislativa2020). Y otros flujos que emergieron a partir de una frase que el presidente dijo en su discurso televisado (hacia "abajo") y transmitido por streaming (de modo "horizontal") que fue: "Somos un gobierno de científicos, no de CEOs" (frase que originó, a su vez, memes satíricos, contracorrientes de sentido). Estudiamos también las diferencias entre distintos hashtags, unos que pre-construyeron el evento (como \#TodosConAlberto, que surgió días antes) y otros que surgieron muy cerca del evento (como \#AbortoLegal y \# AbortoEsPolarizacion). Y estudiamos también, a través de una observación etnográfica, cómo se dispusieron los actores sociales en la Plaza del Congreso. Este último estudio fue muy interesante porque pudimos articularlo con el análisis de la mediatización. Así identificamos con qué hashtags estaban tuiteando los diferentes grupos sociales que ocupaban lugares específicos en la Plaza (La Cámpora, Nuevo Encuentro, organizaciones pro-vida) y pudimos establecer, también, qué contenidos publicaban utilizando esos hashtags distintos individuos. Nada de eso se podría haber hecho sin partir de esta concepción sígnica, relacionista de la circulación.

-La propuesta que hacés en cuanto al estudio de la circulación del sentido en las sociedades hipermediatizadas de la época contemporánea puede entenderse como una apuesta por un nuevo dispositivo analítico, como hemos venido viendo. En este sentido ¿qué novedad aportaría este dispositivo a nuestro campo de investigación?

-Gracias por el reconocimiento. No sé si es para tanto, pero trabajé mucho en estos años para sistematizar los resultados de algunos trabajos que realicé y que realizó el equipo de investigación de la Cátedra Semiótica de Redes de la UBA junto al proyecto $\mathrm{UBACyT}^{4}$ que dirijo para construir un dispositivo analítico, así que lo valoro mucho.

Quizás pueda considerarse novedoso que hubiera tratado de desarrollar un dispositivo que permitiera estudiar la circulación del sentido de las redes sociales a los medios masivos y de los medios masivos a las redes sociales, sin perder el rigor que tiene el modelo de análisis de Verón, proponiendo soluciones para preguntas que son muy importantes actualmente para los investigadores. Una de ellas es, por ejemplo, cómo construir un corpus.

4:: UBA Ciencia y Técnica (UBACyT) es la Secretaría de Ciencia y Técnica de la Universidad de Buenos Aires, que promueve la investigación científica y tecnológica. Miembros del equipo de investigación, apoyado por UBACyT, que dirige Carlón son Damián Fraticelli, Gastón Cingolani, Rocío Rovner, Josefina de Mattei, Noelia Manso, David Taraborelli, Juan Pablo Sokil, Andrea Sol Cialdella, Camila Pereyra, Cristian Blanco, Brenda Buczacki y Verónica Ordóñez. 
¿Qué hice? Creo que realicé, ante todo, dos operaciones. Por un lado, asumi que hoy es casi imposible estudiar todo, porque los corpus a estudiar, cuando los casos son significativos, además de que tienden al infınito, son muy heterogéneos (en un día en el que habla un presidente, hay una manifestación importante, hay miles de tuits, posteos en Facebook, Instagram, horas de transmisión radial y televisiva, comentarios en blogs, etcétera). Por otro lado, establecí que hay fenómenos que sí se deben estudiar y que estaban siendo dejados de lado, además, que son los "saltos" de sistema a sistema y que llamé "hipermediáticos" (ya sea del sistema de medios masivos al de las redes sociales mediáticas o al revés).

Para demostrar esta tesis analicé en profundidad un caso que consideré emblemático de la circulación contemporánea: Chicas Bondi. Es un proyecto post-fotográfico ${ }^{5}$ que retrataba sin permiso a chicas que viajaban en ómnibus en la ciudad de Buenos Aires generado por un enunciador amateur que, a partir de sus publicaciones en Internet (un blog, su cuenta en Twitter), construyó un colectivo de seguidores y despertó el interés de los medios de comunicación masiva (no solo de los medios masivos, sino también de organizaciones feministas que lo denunciaron, pero dejo esta cuestión tan importante para otra conversación porque si no vamos a terminar cambiando de tema). La conclusión a la que llegué fue que, si se focalizan los "saltos" hacia "arriba" y "abajo", de un sistema al otro, que son cambios de escala, es posible construir un corpus.

No se estudia todo, pero lo que se captura es muy importante porque se puede focalizar un conjunto de transformaciones claves que se producen inevitablemente, ya que las lógicas de las redes y las de los medios masivos no son iguales. Es muy importante también porque si, a la vez, se articulan en el análisis dimensiones semióticas, sociológicas, culturales y de la teoría de la mediatización, los resultados que se obtienen exceden claramente los de los tradicionales análisis de la producción del sentido. Se puede comprender, por ejemplo, cómo diacrónicamente un actor/enunciador -que en el caso de Chicas Bondi era además un fake - a partir de determinados medios de comunicación (en este caso sus cuentas en las redes y el blog) construyó un colectivo de seguidores; fue retomado por los medios masivos (que lo consagraron); fue confrontado por una organización contra el acoso callejero (como Hollaback Buenos Aires, que finalmente logró que lo condenara un organismo municipal de la ciudad de Buenos Aires, el Centro de Protección de Datos Personales); reunió un colectivo de seguidores ${ }^{7}$ en espacios públicos como galerías de arte (donde Chicas Bondi hizo una muestra), etcétera.

-Para desarrollar este análisis de Chicas Bondi, como también del resto de los casos que estudiás en tu abordaje de la circulación del sentido, retomás aportes conceptuales de Verón, como ya has señalado. Antônio

5:: La "era post-fotográfica", referida por varios autores, está caracterizada por la generalización de las fotografías digitales, en las que la indicialidad es puesta permanentemente en duda y en las que las fotografías pierden o ven disminuida su función de contribuir a la memoria, a través de recuerdos que quedan registrados materialmente, intensificándose, en cambio, su función de mensaje en las redes sociales mediáticas, a la vez que se da una proliferación inédita de imágenes fotográficas. En el caso de Chicas Bondi, si bien las fotografías son digitales, puesto que son tomadas con un iPhone 4, al ser editadas como si fueran polaroids, con un efecto "retro", refuerzan la dimensión icónica, así como también la indicial. Son, por tanto, imágenes post-fotográficas que funcionan como verdaderas imágenes fotográficas, al tiempo que su carácter digital contribuye a su publicación y propagación en la red (Carlón, 2015).

6:: El enunciador, en la instancia de producción, inicialmente se dio a conocer a través de un nombre de fantasía (Chicas Bondi), lo que generó que quienes estaban ubicados en la instancia de reconocimiento ignoraran todo acerca del enunciador extra-discursivo. Esto cambió más adelante, tras el dictamen del Centro de Protección de Datos Personales, cuando se reveló su identidad extra-mediática.

7:: Este colectivo comenzó en el ámbito mediatizado, pero luego lo trascendió a partir de la puesta en práctica de relaciones intersubjetivas en un espacio social pleno (Carlón, 2019). 
Fausto Neto, en el prólogo a tu último libro, habla de que llevás adelante una "apropiación creativa" de algunos de los planteos teóricos de Verón. ¿Cuál es concretamente tu vínculo con su obra?

-Es un vínculo extenso, que comenzó como lector en la década de los ochenta y que tuvo un momento clave a partir de que accedió a escribir el prólogo de mi segundo libro, Sobre lo televisivo: dispositivos, discursos y sujetos, en 2004. No tenía trato con él, apenas lo había visto una vez fuera de eventos académicos multitudinarios, en una cena en la casa de Oscar Traversa, ${ }^{8}$ en la que prácticamente no habló. Sin embargo, aceptó. Creo que le había gustado mi primer libro, Imagen de arte / imagen de información, publicado en 1994.

Escribí sobre ese vínculo con Verón en un artículo que se publicó en un volumen de homenaje a él (Carlón, 2018). Lo que dije es que, lo que intento hacer, no es una aplicación de su obra, porque no podría haber aplicado su modelo para estudiar Chicas Bondi, por ejemplo, si no hubiera, a la vez, imaginado cómo resolver un conjunto de cuestiones particulares. Por ese entonces, Verón estaba siendo bastante utilizado porque es un autor muy prestigioso y su modelo fue muy efectivo para estudiar la cultura de los medios masivos, pero yo necesitaba hacer algo específico. En general se partía de algo que había formulado Verón, que es que había que estudiar a las instituciones en producción y a los colectivos de actores individuales en reconocimiento. El análisis producía buenos resultados, pero replicaba un esquema mental de la era de los medios masivos aplicado a una nueva situación. Y yo pensaba que todo había cambiado y que ya no había lugares fijos, porque las redes sociales cambiaron el espacio público al habilitar a cada uno la posibilidad de administrar su propio medio de comunicación.

Entonces había que encontrar el modo de estudiar “escenas comunicacionales" en las que, por ejemplo, un individuo podía estar en producción y los medios masivos en reconocimiento (como pasa muchas veces con los youtubers o los tuiteros, cuyos videos son apropiados y comentados por los canales de televisión). Y además estaba la cuestión de los "saltos" de un sistema a otro, que me interesaban mucho y estaban siendo lateralizados. Porque los estudios de redes (ARS) ${ }^{9}$ estaban haciendo grandes aportes, pero no atendian a la relación con los medios masivos. Y porque otros estudios que sí atendian a los "saltos", como los basados en la obra de Henry Jenkins, privilegiaban principalmente ejemplos "descendentes" (de las franquicias a Internet) y luego "ascendentes" (de Internet a los medios masivos de la cultura de fans). Pero a mí me interesaba estudiar otras producciones y otros modos de circulación. Así que lo que hice fue apoyarme en lo que más me interesaba de su obra, que era la distinción entre producción, reconocimiento y circulación, y desarrollar una propuesta que, apoyada en esta distinción, pudiera estudiar otros tipos de circulación entre las redes sociales mediáticas y los medios masivos.

Finalmente, me atreví a realizar una apropiación de su lenguaje visual y a desarrollar gráficos específicos, lo cual probablemente sea, para muchos, una especie de herejía. Aunque quizás no lo sea tanto, porque quien haya leído el prólogo de Verón no debería sorprenderse de que haya realizado en estos años una "apropiación creativa" de su obra. Creo que el primero que advirtió qué es lo que hago con su obra fue, con su gran astucia, el propio

8:: Semiólogo, docente y escritor argentino. Se graduó en 1973 en Artes por la École des Hautes Études en Sciences Sociales de París, bajo la dirección de Christian Metz; disciplina en la que se doctoró en la Universidad de Buenos Aires en 1996. Investigó las relaciones entre la producción mediática y el campo estético en el discurso cinematográfico y el de la prensa, asi como los modos de construcción de los espacios públicos y privados a través de la figuración del cuerpo en los medios y la producción artística. En 1974, publicó la revista de lingüística y semiología LENGUAjes junto a Verón, Oscar Steimberg y Juan Carlos Indart.

9:: El Análisis de Redes Sociales (ARS) es una perspectiva particular dentro de las Ciencias Sociales que surge a partir de los aportes de diferentes ciencias: sociología, psicología, antropología, psicología, matemáticas. Su enfoque metodológico y teórico enfatiza el estudio de las relaciones entre diversos actores. 
Verón, quien dice en ese texto que en el libro lo "uso" y que ese uso le produce una "inquietante extrañeza", pero que no cree que sea algo singular, sino propio de la circulación. Y, según recuerdo, nunca le molestaron mis apropiaciones de su obra, así que duermo bastante tranquilo (se ríe).

-En diferentes trabajos aludís a tres momentos históricos distintos: la época moderna, la postmoderna y la contemporánea ¿Cuáles son los cambios más significativos en lo que se refiere a la comunicación entre estos períodos?

-Mi impresión es que estamos viviendo un big bang, un cambio de época, el pasaje a una sociedad hipermediatizada en la que hay más de un sistema mediático y no solo el de los medios masivos (actualmente estoy considerando un tercer sistema, que contiene Zoom, WhatsApp, etcétera, pero dejémoslo de momento de lado). Sobre todo, porque se articuló con una adopción general de las redes sociales, de múltiples actores/enunciadores que empezaron a utilizarlas, a comunicarse entre sí. Obviamente, en este cambio aparecieron las grandes corporaciones globales, que tampoco son tan hegemónicas, como a veces se piensa, porque se olvida de que en China hay otras redes sociales, por ejemplo, y que ese escenario corporativo global puede cambiar. Pero lo que me parece más importante, y que no va a volver atrás, es que a partir de la aparición de nuevos actores/enunciadores se ha desencadenado una transformación de los espacios públicos que ya no son hegemónicamente dominados, como antes, por pocos. Y que ese cambio vino acompañado por una transformación en la circulación del sentido producida por enunciadores orgánicos finitos que se dedican a contar sus dolencias, sus alegrías, sus viajes; a establecer relaciones con actores lejanos, con actores que están "arriba” o "abajo”; a transformar sus vidas, es decir, que ahora hay otros actores/enunciadores en la escena pública de la cual formamos parte todos, desde el más importante al menos importante, apropiándonos de discursos, comentándolos, produciéndolos, poniéndolos a circular.
Este cambio es tan importante que ha generado muchas transformaciones. Una de ellas es la irrupción de un poder que es distinto del "poder de los enunciadores", que era el de los poderosos en la vida social. Ha generado que se advierta claramente que además hay un "poder de la circulación del sentido" que se manifiesta, porque no todo lo que ponen a circular los poderosos (los políticos, los conocidos, los jugadores de fútbol profesionales, las celebrities...) se vuelve siempre relevante en términos circulatorios. Y porque lo que producen los no poderosos tiene muchas veces el poder de llegar desde "abajo" hacia "arriba”, de las redes sociales a los medios masivos y de generar acciones en los espacios públicos, en las plazas, en la calle, en las galerías de arte, además de desnudar muchas veces al poder constituido, institucional.

La irrupción abrupta de la circulación como un fenómeno dominante y expuesto, junto con este poder de la circulación que tiene sus propias lógicas, hace que los que estudiamos estos fenómenos enfrentemos grandes desafíos para pensar a las polarizadas sociedades contemporáneas. Un artículo que está por publicarse sobre este tema me obligó a reflexionar recientemente sobre este fenómeno. ${ }^{10}$ La pregunta que tuve que enfrentar fue: ¿cómo sociedades que se caracterizan por la circulación como diferencia se encuentran tan polarizadas? ¿Por qué no están más fragmentadas aún?, que es lo que sería lógico hipotetizar que debería haber sucedido, si atendemos a los análisis que diagnosticaron la liquidez de las sociedades posmodernas y su progresiva articulación con las nuevas condiciones de mediatización y circulación. La respuesta a la que llegué, provisoria obviamente, fue que se debe a que no son fenómenos necesariamente contradictorios. Que en una sociedad haya, por ejemplo, dos polos dominantes, no impide que la circulación domine incluso en el interior de los polos. La lógica de la polarización está impuesta,

10:: Se refiere a un trabajo escrito para el III Seminario Internacional sobre Mediatizaciones y Procesos Sociales realizado en la Universidad de Unisinos, Brasil, en 2019, cuyo tema fue "Mediatización, polarización e intolerancia". 
en gran medida, por la alternancia democrática, por la obligación de tener que elegir entre dos fuerzas, incluso por los sistemas de ballotage, tan expandidos. Pero eso no impide que cada actor/enunciador que administra su propio medio de comunicación pueda (y prácticamente deba, según parámetros de la época) definir su propio modo de participar en cada polo, acción que realiza a cada momento decidiendo qué discurso produce, con quién tiene un matiz, qué discurso comparte o pone a circular, qué meme le gusta, etcétera. Mi tesis, entonces, es que el crecimiento de los polos no es incompatible con el concepto de circulación como diferencia. Es más, es probable que en sociedades democráticas en las que se goza de una libertad de expresión mayor que en las anteriores, con más posibilidades de poner la opinión a circular, los polos crezcan, incluso más, cuanta más diferencia y creatividad permitan, cuantos más enunciadores encuentren en ellos su propio modo de expresarse y de identificarse. Es una tesis interesante ¿no? Los polos que crecen son los que, más que basarse en consensos hegemónicos, soportan la circulación contemporánea. Y se enriquecen con ella. Con la actividad múltiple y compleja de sus actores sociales e individuales. No sé si es verdadera, habría que intentar demostrarla, pero me parece que da mucho para pensar.

\section{- ¿Has pensado algún abordaje para demostrar esta tesis? ¿Por dónde empezarías?}

-Demostrar ese tipo de tesis no es sencillo, dada la complejidad creciente de las sociedades hipermediatizadas, que cuentan, como señalé, con más de un sistema mediático y una increíble cantidad de producción de contenidos. Creo que la investigación que presentamos sobre la construcción contemporánea de un evento, el discurso de apertura de las sesiones ordinarias de Alberto Fernández en 2020 al que hice referencia, es un ejemplo de lo que estoy diciendo (Midiaticom, 2020). El análisis parte de la consideración de la polarización que existe en la Argentina a partir del resultado de las últimas elecciones presidenciales. Y muestra, creo que con bastante detalle, cómo distintos actores sociales (agrupaciones políticas, militantes, políticos, humoristas, colectivos a favor y en contra del aborto, actores individuales presentes y ausentes en la plaza) se ubican en estos polos, pero lo hacen encontrando cada uno su propio modo de manifestarse mediáticamente (por ejemplo, apropiándose de los hashtags de modo específico).

Son investigaciones difíciles de hacer, porque requieren la participación de muchos investigadores, con saberes diferentes, que dedicamos días enteros de trabajo a relevar lo que acontece en un acontecimiento. Y luego, por supuesto, al análisis. Pero si uno pudiera realizar análisis de varios acontecimientos relativamente comparables entre sí (por ejemplo, otros discursos de apertura) a lo largo de los años y a eso le sumara un análisis semejante de otros acontecimientos importantes, estoy seguro de que lograría resultados significativos. En los polos actuales hay voces institucionales, por supuesto. Y son importantes. Pero a la vez hay miles de actores individuales que administran, con múltiples recursos productivos, sus propios medios de comunicación. Una investigación como la que hicimos asume la co-presencia contemporánea. Pero lo hace, a diferencia de otras investigaciones, por ejemplo filosóficas, a partir de un conocimiento de los intercambios efectivos que se realizan a través de la mediatización y la circulación.

En nuestra contemporaneidad, los polos organizan, en gran medida, el espacio social brindando marcos contenedores, de pertenencia. Pero debido a las transformaciones que caracterizan a la época -las nuevas tensiones sociales, políticas y económicas que ponen en discusión constantemente principios como la libertad y la igualdad, que se encuentran en la base del sistema democráticoestos polos se encuentran sometidos a procesos dinámicos y se reconfiguran continuamente. En el análisis de estas manifestaciones, las diferencias que identifican los análisis de la circulación no son menores, son específicas. El desafío entonces es atender a la polarización, pero sin dejar de lado las diferencias, las que se producen constantemente como producto de la mediatización y la circulación contemporáneas. 


\begin{abstract}
Mario Carlón
Doctor en Ciencias Sociales por la Universidad de Buenos Aires (UBA) y licenciado en Historia del Arte por la Universidad Nacional de La Plata. Es investigador del Instituto Gino Germani de la Facultad de Ciencias Sociales de la UBA, donde tiene radicado el Proyecto de Investigación UBACyT "La mediatización en el entretejido de los vínculos sociales". Es profesor titular a cargo de Semiótica de Redes en la Carrera de Comunicación de la Facultad de Ciencias Sociales de la UBA. Fue presidente de AsAECA (Asociación Argentina de Estudios sobre Cine y Audiovisual, 2013-2015). Entre sus libros publicados se encuentran: Circulación del sentido y construcción de colectivos en una sociedad hipermediatizada (Nueva Editorial Universitaria, 2020); Después del fin. Una perspectiva no antropocéntrica sobre la post-tv, el postcine y YouTube (La Crujía, 2016); 0 fim da televisão (Confraria do Vento, 2014) junto a Yvana Fechine; El fin de los medios masivos. El debate continúa (La Crujia, 2014) y Colabor_arte. Medios y arte en la era de la producción colaborativa (La Crujía, 2012), ambos en colaboración con Carlos A. Scolari; Las políticas de los internautas. Nuevas formas de participación (La Crujía, 2012) conjuntamente con Antônio Fausto Neto; De lo cinematográfico a lo televisivo. Metatelevisión, lenguaje y temporalidad ((La Crujía, 2006); y Sobre lo televisivo: dispositivos, discursos y sujetos (La Crujía, 2004).
\end{abstract}

\section{Referencias}

Carlón, M. (1994). Imagen de arte/imagen de información. Problemas actuales de la relación entre el arte y los medios. Buenos Aires, Argentina: Atuel.

Carlón, M. (2004). Sobre lo televisivo: dispositivos, discursos y sujetos. Buenos Aires, Argentina: La Crujía.

Carlón, M. (2015). Público, privado e íntimo: el caso Chicas Bondi y el conflicto entre derecho a la imagen y libertad de expresión en la circulación contemporánea. En P. César Castro (Org.), Dicotomia público/privado: estamos no caminho certo? (pp. 211-232). Maceió, Brasil: EDUFA.

Carlón, M. (2018). Sur les pas de Verón... Une approche des nouvelles conditions de circulation du sens à l'ère contemporaine. Communication \& langages, 2(2), 99-120. https://doi. org/10.3917/comla1.196.0099

Carlón, M. (2019). Individuos y colectivos en los nuevos estudios sobre circulación. InMediaciones de la Comunicación, 14(1), 27-46.

Carlón, M. (2020). Circulación del sentido y construcción de colectivos en una sociedad hipermediatizada. San Luis, Argentina: Nueva Editorial Universitaria - UNSL.

Debrock, G. (1991). La información y el estatuto metafísico de los signos. Comunicación y Sociedad, 4, 53-64.

Facultad de Ciencias Sociales UBA. (28 de octubre de 2020). Diálogos en la Biblioteca | Libro: "Circulación del sentido y construccion de colectivos en..." [Video]. Youtube. Recuperado de http:// www.sociales.uba.ar/2020/10/28/presentacion-libro-circulacion-del-sentido-y-construccion-de-colectivos-en-una-sociedad-hipermediatizada/

Midiaticom. (25 de noviembre de 2020). IVSeminário Midiatização - Mesa 3 - Novos Processo de Midiatização e Circulação - Mario Carlón [Video]. Youtube. Recuperado de https://www.youtube. com/watch?v=JlgX1X19pPE

Schaeffer, J. M. (1990). La imagen precaria: del dispositivo fotográfico. Madrid, España: Cátedra.

Verón, E. (1987). Construir el acontecimiento. Buenos Aires, Argentina: Gedisa.

Contribución autoral

a) Concepción y diseño del trabajo; b) Adquisición de datos; c) Análisis e interpretación de datos; d) Redacción del manuscrito; e) revisión crítica del manuscrito.

G. A. ha contribuido en $a, d$, e.

Editor responsable: L. D. 